\title{
Wet spinning of integrally skinned hollow fiber membranes by a modified dual-bath coagulation method using a triple orifice spinneret
}

\author{
S.-G. Li, G.H. Koops, M.H.V. Mulder, T. van den Boomgaard *, C.A. Smolders \\ Faculty of Chemical Technology, University of Twente, P.O. Box 217, 7500 AE Enschede, Netherlands
}

(Received September 23, 1993; accepted in revised form March 8, 1994)

\begin{abstract}
Three main routes are known to prepare hollow fiber membranes: melt spinning, dry spinning and wet spinning (or dry/wet spinning). The latter is the most important technique for the preparation of industrial hollow fiber membranes. In this process the extruded polymer solution is immersed in a nonsolvent bath where phase separation occurs. Generally there is an air gap between the spinneret and nonsolvent and this air gap has a large impact on the ultimate membrane properties. In order to control the processes in this air gap a new type of spinneret has been developed where the extrusion mouth has three openings. The membrane formation process can be controlled by the choice of the nonsolvent which is extruded through the outer opening as a thin film adhering to the polymer solution. In this way both asymmetric microfiltration and ultrafiltration hollow fibers can be prepared as well as integrally skinned hollow fibers with a defect-free top layer suitable for gas separation and pervaporation. The advantage of this spinneret in relation to the phase inversion process will be described and some examples will be given in the field of gas separation and pervaporation.
\end{abstract}

Key words: fiber membranes; gas separations; pervaporation; spinneret

\section{Introduction}

The development of commercial reverse osmosis seawater desalination membranes has been of great influence on the development of hollow fiber membranes. Nowadays hollow fiber membranes are used in a wide range of applications. The primary advantage of hollow fibers over other configurations is the large surface area over volume ratio. There are three main techniques: melt spinning, dry spinning and wet spinning (or dry/wet spinning) [1,2].

*Corresponding author.
In melt spinning the polymer is heated above its melting point in an inert atmosphere and then the liquid polymer is extruded through a spinneret $[3,4]$. By immediate cooling a phase transition occurs and the polymer solidifies. In this way a capillary or hollow fiber is obtained with a uniform structure. By stretching very thin fibers can be obtained with diameters less than $50 \mu \mathrm{m}$ and a wall thickness of $\sim 5 \mu \mathrm{m}$. The spinning rate is very high and can be over 1000 meters per minute.

Another method for preparing hollow fiber membranes which makes use of a cooling step, employs a polymer and a latent solvent [5]. A 
latent solvent means that it is a good solvent for a polymer at high temperature and becomes a nonsolvent at low temperature. The polymer solution is thermodynamically stable at high temperature. By lowering the temperature the loss of solvent power will first cause liquid-liquid demixing of the solution and further cooling will lead to crystallisation or vitrification of the demixed solution. Usually, this process is used to prepare microfiltration membranes from polyolefins [5].

In the dry spinning technique the polymer is dissolved in a very volatile solvent. After extrusion the polymer solution is heated and because of evaporation of the solvent the polymer will solidify. Also in this way very thin fibers may be obtained.

With these separate techniques it is hardly possible to prepare selective gas separation membranes with a high permeability. Usually a combination of different techniques have been employed to obtain the desired properties. Henis and Tripodi [6] prepared asymmetric membranes with a certain porosity in the top layer. These substrates were coated with a thin layer of an elastomeric polymer, which has a high permeability but a low selectivity. These composite membranes showed high selectivities combined with high permeabilities.

Another combined technique for preparing dense gas separation membranes has been described by Kesting [7]. In this case a combination of solvents with a difference in boiling point of $\sim 30-40 \mathrm{~K}$ was applied. Partial evaporation of the volatile solvent before immersion in the coagulation bath leads to a concentrated polymer layer at the interface. Immersion in the nonsolvent bath leads then to the formation of asymmetric membranes with a dense top layer.

Variation of these techniques have been described, e.g., by Peinemann and Pinnau [8] and by Koros et al. [9-12].

The majority of the hollow fibers employed in technical membrane processes are spun by a wet spinning (or dry/wet spinning) technique. Any type of membrane morphology can be obtained with this technique since many parameters involved can be varied. Here the polymer solution is extruded into a nonsolvent bath where demixing occurs because of exchange of solvent and nonsolvent. Between the spinneret and nonsolvent bath there is an air gap where in fact the membrane formation starts. This implies that a good control of this phase is a first requirement. This is especially the case for the preparation of integrally skinned hollow fibers for gas separation and pervaporation since the top layer must be completely defect-free. The tube-in-orifice spinneret which is now mainly used for this wet spinning technique has the disadvantage that the conditions in the air gap are difficult to control. Therefore a new triple orifice spinneret has been developed which allows a much better control of the conditions applicable for the spinning of all types of hollow fibers. In this article we will report on the characteristics of this spinneret with respect to the preparation of defect-free integrally skinned hollow fibers for gas separation and pervaporation. At first some basic principles of membrane preparation will be given followed by the results obtained with this spinneret for gas separation and pervaporation membranes from polysulphone (PSf) and polyethersulphone (PES). Also asymmetric porous microfiltration and ultrafiltration membranes can be prepared with this spinneret [13].

For the preparation of commercial membranes the phase inversion process $[14,15]$ is generally applied. In this process a polymer solution is immersed into a nonsolvent bath where phase separation (liquid-liquid demixing) occurs as a result of the exchange of solvent and nonsolvent. After solidification of the polymer an asymmetric membrane with a relatively dense top layer remains.

In a study about membrane formation Reu- 
vers and Smolders [16] distinguished two different demixing processes, viz. (i) delayed demixing, where the ratio of solvent outflow and nonsolvent inflow is relatively large, which results in a certain time interval between immersion of the polymer solution in the nonsolvent bath and the onset of demixing, and (ii) instantaneous demixing, where liquid-liquid demixing takes place immediately after the polymer solution is in contact with the nonsolvent.

Due to the relatively large outflow of solvent in the delayed demixing process a net loss of liquid results in densification at the interface. By the time liquid-liquid demixing occurs the polymer concentration at the interface has become so high that the vitrification boundary is crossed. After solidification a dense interfacial layer is formed. Underneath the interfacial layer the polymer concentration will also increase, but to a much smaller extent compared to the interfacial layer itself. Generally, membranes prepared by a delayed demixing process will be intrinsically selective in gas separation and pervaporation, but have a relatively high transport resistance.

Instantaneous demixing also involves an increase of the polymer concentration at the interfacial layer. However, this layer is very thin and, in general, is slightly porous. The polymer concentration in the sublayer has almost no time to change before liquid-liquid demixing occurs. Only when started with a high polymer concentration membranes might be formed with gas separation and pervaporation properties, although they will have a high transport resistance. Generally, porous membranes are formed by the instantaneous demixing process.

Van 't Hof et al. $[17,18]$ were the first who studied the feasibility of these concepts by using a combination of delayed demixing and instantaneous demixing to prepare selective gas separation membranes. Firstly, they immersed (for a short time) a cast film or extruded fiber in a nonsolvent which may induce delayed de- mixing followed by immersion in a second nonsolvent which demixes the polymer solution instantaneously. It was shown that both flat films and hollow fiber membranes with intrinsic selectivities for the separation of $\mathrm{CO}_{2} / \mathrm{CH}_{4}$ could be obtained by this dual-bath method.

In the spinning process, van 't Hof et al. $[17,18]$ immersed the nascent fiber in two different nonsolvents successively. Practically, they used two different methods to realise this.

In the first method a nonsolvent bath consisting of two immiscible liquids was used. This can only be employed when the first nonsolvent (causing delayed demixing) has a lower density than the second nonsolvent (causing instantaneous demixing). Pentanol was used as the first nonsolvent and water as the second nonsolvent. Nevertheless, problems occurred after a certain time when the pentanol layer became saturated with water. Although the solubility of water in pentanol is only $9.2 \mathrm{wt} \%$, this appeared to be enough to prevent delayed demixing in the first nonsolvent and in turn resulted in nonselective fibers.

In the second method two separate coagulation baths were used. The first nonsolvent was highly viscous (glycerol) and was added continuously into a funnel with a small opening at the bottom (first bath). After passing this bath the nascent fiber coated with a relatively thick nonsolvent layer entered the second coagulation bath filled with water, where instantaneous demixing occurred after the first nonsolvent had been removed from the fiber wall. This method can only be employed when highly viscous nonsolvents are used as the first coagulant; otherwise too much nonsolvent has to be added. Due to the high viscosity, a relatively thick glycerol layer adhered around the fiber wall which was very difficult to be removed in the second bath. Consequently, liquid-liquid demixing of the polymer solution could not take place immediately upon the immersion of the fiber into the second nonsolvent bath. There- 
fore, the actual contact time with the first nonsolvent was much higher than the one calculated from the spinning speed and the distance between the spinneret and the second nonsolvent bath. This method resulted in top layers of $\sim 2 \mu \mathrm{m}$ thick. For the dual-bath process in general, the longer the contact time with the first nonsolvent is the thicker the top layer will be.

To control the contact time with the first nonsolvent and to be able to use all kinds of nonsolvents that result in delayed demixing, a spinneret has been developed with a tube and two orifices [19] (Fig. 1); one capillary tube for the bore liquid (1), one orifice for the polymer solution (2) and one orifice for the first nonsolvent (3). Together these three streams enter the coagulation bath (4) which contains the second nonsolvent. Due to the small opening a very thin layer of nonsolvent is adhered to the fiber wall and therefore a relatively small amount of first nonsolvent will be used in the spinning process. A thin layer causes a faster

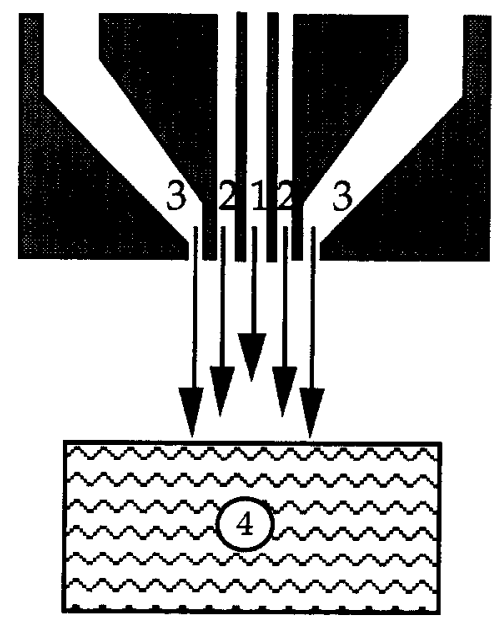

Fig. 1. Schematic representation of the triple orifice spinneret with coagulation bath. The dimensions of the spinneret are: inner diameter (i.d.) $0.20 \mathrm{~mm} /$ outer diameter (o.d.) $0.35 \mathrm{~mm}$ for the center tube; i.d. $0.35 \mathrm{~mm} /$ o.d. 0.75 $\mathrm{mm}$ for the internal orifice and i.d. $1.00 \mathrm{~mm} / \mathrm{o} . \mathrm{d} .1 .5 \mathrm{~mm}$ for the outer orifice. 1, Bore liquid; 2, polymer solution; 3 , first coagulation bath; 4 , second coagulation bath. penetration of the second nonsolvent. By varying the distance between the outlet of the spinneret and the coagulation bath the contact time with the first nonsolvent can be controlled. Besides, less viscous solvents than glycerol can be used.

Other advantages of the use of this type of spinneret are: (i) there are no restrictions with respect to the first nonsolvent, (ii) the first nonsolvent will never get saturated with the second nonsolvent, (iii) the temperature of the two different nonsolvents can be controlled independently, (iv) the pollution of the second nonsolvent with the first nonsolvent is relatively small and, last but not least, (v) the spinning process is extremely easy to handle, while many spinning parameters can be varied.

It has been shown $[13,20]$ that by a proper choice of the first coagulant, ultrafiltration and microfiltration hollow fibers can also be obtained.

Another possibility with this spinneret, which has not yet been explored by us, is the use of a second polymer solution. This can be pumped through the outer orifice to obtain a selective coating at the outside of the fiber.

\section{Experimental}

\subsection{Materials}

The polymers used were polyethersulphone (PES, Victrex 5200P from ICI) and polysulphone (PSf, Udel 3500 from Amoco). Before use the polymers were dried at $150^{\circ} \mathrm{C}$ under vacuum. Silicon rubber (RTV 106, General Electric) was obtained from Benecom B.V. The solvents used in the spinning dope and as the first coagulant were $N$-methylpyrrolidone (NMP) (synthesis grade), glycerol (water free, extra pure), isopropanol (analytical grade) and acetic acid (analytical grade); they were obtained from Merck and were used without further purification. 


\subsection{Hollow fiber spinning}

The spinning solutions were prepared by addition of the polymer into a well-stirred NMP/ glycerol mixture at a temperature of $60-80^{\circ} \mathrm{C}$. After the polymer was dissolved the solution was filtered over a $25 \mu \mathrm{m}$ stainless steel filter and degassed overnight at the ultimate spinning temperature.

The spinning process was performed with the triple orifice spinneret (Fig. 1). During the spinning a first coagulant (nonsolvent) was pumped through the outmost orifice of the spinneret; the polymer solution and the bore liquid were pumped through the corresponding orifices as illustrated in Fig. 1. Glycerol or a mixture of glycerol and isopropanol were used as the first coagulant, and water was used as the bore liquid and as the second coagulant.

The fibers obtained were dried in air after rinsing in running water for two days followed by immersion in ethanol for $8 \mathrm{~h}$ and then in hexane for another $8 \mathrm{~h}$. For PES hollow fibers, only results are given for those dried in air directly after 2 days rinsing in running water. The reason for this is that the presented results for PES fibers in this paper are used to compare with the results obtained by van ' $t$ Hof et al. [18] who used the same drying procedure. This was done because it is known that the drying procedure can have a great impact on the final properties of membranes (including those produced by the dual-bath method) $[18,21]$. The effect of different drying procedures on the properties of PES hollow fibers spun with the modified dual-bath process has been investigated and is described elsewhere [20].

\subsection{Gas separation}

The permeation set-up used for gas separation measurements was the same as described by van 't Hof et al. [18]. For each type of fiber, at least three test modules each containing 3 fibers with a length of 10 to $14 \mathrm{~cm}$ were prepared and measured with a feed gas of 20-25 vol\% $\mathrm{CO}_{2}$ in $\mathrm{CH}_{4}$ at a pressure of $\sim 6-8$ bar and a temperature of $22-24^{\circ} \mathrm{C}$. The modules were tested with the feed stream at the shell side. The time of conditioning before each measurement was at least $30 \mathrm{~min}$. The accuracy of the reported selectivities and permeabilities is within $5 \%$.

The intrinsic selectivity of PES for $\mathrm{CO}_{2} / \mathrm{CH}_{4}$ $(25 / 75 \mathrm{vol} \%)$ was obtained to be $\sim 52-55$ while the permeability for $\mathrm{CO}_{2}$ was measured to be 3.0 barrer in the case of homogeneous flat films (measured at a pressure of 5 bar and room temperature). This selectivity is somewhat larger than the one obtained by Ellig et al. [22]. They found for a $25 \mu \mathrm{m}$ PES film a value of 40 with a permeability of $3 \times 10^{-10} \mathrm{~cm}^{3} \mathrm{~cm} / \mathrm{cm}^{2} \mathrm{~s} \mathrm{cmHg}$. This was measured for a $60 / 40 \mathrm{vol} \% \mathrm{CO}_{2} / \mathrm{CH}_{4}$ mixture at $2068 \mathrm{kPa}$ and $25^{\circ} \mathrm{C}$.

The intrinsic selectivity measured for a dense PSf film for $\mathrm{CO}_{2} / \mathrm{CH}_{4}(25 / 75 \mathrm{vol} \%)$ was 3133 , while the permeability for $\mathrm{CO}_{2}$ was measured to be 8.3 barrer (measured at a pressure of 5 bar and room temperature).

\subsection{Pervaporation}

The hollow fiber membranes for pervaporation were tested using a feed mixture of $80 \mathrm{wt} \%$ acetic acid and $20 \mathrm{wt} \%$ water at a temperature of $70^{\circ} \mathrm{C}$. Modules consisting of two fibers at a length of $\sim 15 \mathrm{~cm}$ were made. A one component silicon rubber (RTV 106) was used as potting material. The permeate side was maintained at a pressure of $0.1-0.2 \mathrm{mmHg}$ by an Edwards twostage vacuum pump. The pressure was measured by an Edwards Pirani meter. Permeate samples were taken every hour during $8 \mathrm{~h}$ testing. Steady state was normally obtained after $2-3 \mathrm{~h}$. The permeate was analysed using a Varian 3700 Gas Chromatograph filled with a Poropack Q column at a temperature of $190^{\circ} \mathrm{C}$. A schematic representation of the pervaporation 
set-up is given in Fig. 2. The accuracy of the reported selectivities and permeabilities is within $5 \%$.

The selectivity and flux of a $20 \mu \mathrm{m}$ thick PSf membrane for dehydration of $80 \mathrm{wt} \%$ acetic acid at $80^{\circ} \mathrm{C}$ by pervaporation are 623 and $0.037 \mathrm{~kg}$ $\mathrm{m}^{-2} \mathrm{~h}^{-1}$, respectively [23]. These values are obtained after annealing the membrane at $200^{\circ} \mathrm{C}$ for $1 \mathrm{~h}$ to reduce the sensitivity for stresscracking induced by the solvent. No reliable intrinsic permeation properties of pure acetic acid could be obtained. This was caused as well by stress-cracking induced by the pure acetic acid which results in leakage of the membranes. Neither reliable data for pure water could obtained due to the very low permeativity.

\subsection{Scanning electron microscopy}

Samples for scanning electron microscopy (SEM) were made by cryogenic breaking of the fibers after being soaked in a water/ethanol mixture. The broken samples were dried under vacuum and coated with a thin gold layer by means of sputtering. A Jeol JSM-T 220A Scanning Microscope was used.

\section{Results and discussion}

\subsection{Gas separation}

To obtain a membrane with a highly dense top layer, a nonsolvent which induces delayed demixing of the polymer solution has to be used as the first coagulant in a dual-bath spinning process. Van 't Hof et al. [17,18] showed that glycerol is a suitable first coagulant to obtain highly selective gas separation hollow fiber membranes from a spinning solution of $35 \%$ PES, $60 \%$ NMP and $10 \%$ glycerol by this process. For reasons of comparison, the same polymer solution and first coagulant as used by van 't Hof were also used here, while all other parameters were kept constant except for the spinneret. The gas permeation properties of PES hollow fibers spun with the use of the new

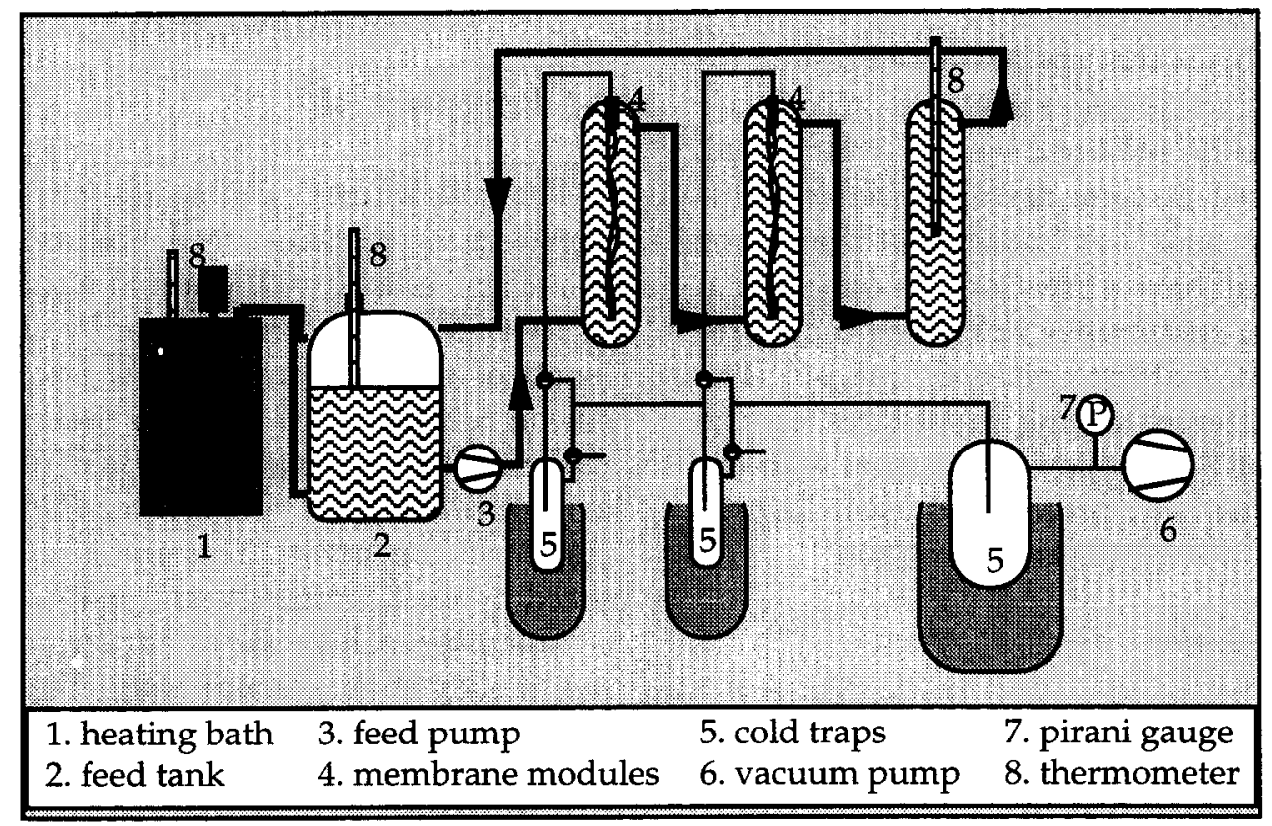

Fig. 2. Schematic representation of the pervaporation set-up. 
TABLE 1

Comparison of the properties of the PES fiber made by the modified dual-bath process with the properties of the fiber in the literature [18]

\begin{tabular}{lll}
\hline Fibers & $\begin{array}{l}\text { Selectivity } \\
\alpha\left(\mathrm{CO}_{2} / \mathrm{CH}_{4}\right)\end{array}$ & $\begin{array}{l}P / l^{\mathrm{a}} \\
\left(\mathrm{CO}_{2}\right)\end{array}$ \\
\hline $\begin{array}{l}\text { Fiber made by the modified } \\
\text { dual-bath process }\end{array}$ & 52 & 3.6 \\
$\begin{array}{l}\text { Fiber as reported in the } \\
\text { literature [18] }\end{array}$ & 52 & 2.5 \\
\hline
\end{tabular}

${ }^{a} 10^{-6} \mathrm{~cm}^{3} / \mathrm{cm}^{2} \mathrm{~s} \mathrm{cmHg}$.

Conditions. Spinning solution: 35\% PES, 55\% NMP, $10 \%$ glycerol; flow rate: $1.2 \mathrm{ml} / \mathrm{min}$; temperature: $60^{\circ} \mathrm{C}$. First coagulant: glycerol; flow rate: $3.5 \mathrm{ml} / \mathrm{min}$; temperature: $20^{\circ} \mathrm{C}$. Gap length: $80 \mathrm{~mm}$. Bore liquid: water; flow rate: 0.6 $\mathrm{ml} / \mathrm{min}$; temperature: $20^{\circ} \mathrm{C}$. Second nonsolvent: water; temperature: $20^{\circ} \mathrm{C}$. Both fibers were dried in air without pre-immersion into ethanol and hexane.

spinneret are shown in Table 1 together with the properties of the fiber made by van 't Hof.

From these results it can be seen that the fiber spun with the use of the triple orifice spinneret showed the same selectivity but a higher permeability compared to the fiber prepared with the conventional tube-in-orifice spinneret. This is due to a better control of the contact time between the polymer solution and the first coagulant. To obtain a thin skin the contact time with the first nonsolvent has to be short. With the use of the triple orifice spinneret, the amount of glycerol used as first coagulant was rather small. In the case of the dualbath method applied with the conventional tube-in-orifice spinneret a relatively thick glycerol layer adhered to the nascent fiber wall [18]. Because of the high viscosity of glycerol it takes a certain time for the removal of this thick layer from the nascent fiber and for the second nonsolvent to reach the polymer solution. Reduction of the glycerol layer thickness will result in a faster removal of this layer from the fiber surface in the second bath and consequently a thinner top layer of the resulting fiber could be obtained.
In principle it should be possible to control the contact time between the polymer solution and the first coagulant by changing the gap length between the spinneret and the second bath. By reducing the gap length, a short contact time is expected and thus a thin skin would result.

The influence of changing gap length on the properties of the resulting fibers is shown in Table 2. The contact time listed here is calculated according to the gap length and the spinning speed.

From Table 2 it becomes evident that hollow fibers with intrinsic selectivity could be obtained. An increase in flux with reduction of the gap length, which was expected, was not obtained. Eventually, the fluxes of all the fibers were nearly the same. The reason for this is probably still due to the difficulty for the water molecules to reach immediately the polymer solution itself. It was namely observed that after immersion of the nascent fiber into the second bath the fiber was still surrounded by a thin layer of glycerol of $450 \pm 50 \mathrm{~mm}$. This means that the actual contact time between the spin-

\section{TABLE 2}

The influence of changing gap length on the properties of the resulting PES fibers

\begin{tabular}{clll}
\hline $\begin{array}{l}\text { Gap length } \\
(\mathrm{mm})\end{array}$ & $\begin{array}{l}\text { Contact time } \\
(\mathrm{s})\end{array}$ & $\begin{array}{l}\text { Selectivity } \\
\alpha\left(\mathrm{CO}_{2} / \mathrm{CH}_{4}\right)\end{array}$ & $\begin{array}{l}\mathrm{P} / l^{\mathrm{a}} \\
\left(\mathrm{CO}_{2}\right)\end{array}$ \\
\hline 0 & 0 & 41 & 3.2 \\
5 & 0.04 & 41 & 3.2 \\
17 & 0.14 & 48 & 3.2 \\
35 & 0.29 & 52 & 3.4 \\
80 & 0.66 & 52 & 3.6 \\
100 & 0.82 & 52 & 3.2 \\
\hline
\end{tabular}

${ }^{\mathrm{a}} 10^{-6} \mathrm{~cm}^{3} / \mathrm{cm}^{2} \mathrm{~s} \mathrm{cmHg}$.

Conditions. Spinning solution: $35 \%$ PES, 55\% NMP, $10 \%$ glycerol; flow rate: $1.2 \mathrm{ml} / \mathrm{min}$; temperature: $60^{\circ} \mathrm{C}$. First coagulant: glycerol; flow rate: $3.5 \mathrm{ml} / \mathrm{min}$; temperature: $20^{\circ} \mathrm{C}$. Bore liquid: water; flow rate: $0.6 \mathrm{ml} / \mathrm{min}$; temperature: $20^{\circ} \mathrm{C}$. Second nonsolvent: water; temperature: $20^{\circ} \mathrm{C}$. Fibers were dried in air without pre-immersion into ethanol and hexane. 


\section{TABLE 3}

The influence of flow rate of glycerol as the first coagulant on the properties of the resulting PES fibers, with turbulence in the second coagulation bath

\begin{tabular}{lll}
\hline $\begin{array}{l}\text { Flow rate of glycerol } \\
\text { as the first } \\
\begin{array}{l}\text { coagulant } \\
(\mathrm{ml} / \mathrm{min})\end{array}\end{array}$ & $\begin{array}{l}\text { Selectivity } \\
\alpha\left(\mathrm{CO}_{2} / \mathrm{CH}_{4}\right)\end{array}$ & $\begin{array}{l}\mathrm{P} / l^{\mathrm{a}} \\
\left(\mathrm{CO}_{2}\right)\end{array}$ \\
\hline 0.5 & & \\
1.5 & 13 & 6.0 \\
2.5 & 32 & 4.5 \\
3.5 & 36 & 3.9 \\
\hline
\end{tabular}

${ }^{a} 10^{-6} \mathrm{~cm}^{3} / \mathrm{cm}^{2} \mathrm{~s} \mathrm{cmHg}$.

Conditions. Spinning solution: $35 \%$ PES, $55 \%$ NMP, $10 \%$ glycerol; flow rate: $1.2 \mathrm{ml} / \mathrm{min}$; temperature: $60^{\circ} \mathrm{C}$. First coagulant: glycerol; temperature: $20^{\circ} \mathrm{C}$. Gap length: $80 \mathrm{~mm}$. Bore liquid: water; flow rate: $0.6 \mathrm{ml} / \mathrm{min}$; temperature: $20^{\circ} \mathrm{C}$. Second nonsolvent: water; temperature: $20^{\circ} \mathrm{C}$. Fibers were dried in air without pre-immersion into ethanol and hexane.

ning solution and glycerol should be the calculated contact time (in Table 2 ) plus $\sim 4 \mathrm{~s}$. This estimation is based on the flow rate of the spinning solution and the "sticking" length. Thus the actual contact time changed from $\sim 4$ to 5 $\mathrm{s}$ which can hardly be lowered by variation of the gap length. To diminish the contact time, other nonsolvents with a lower viscosity should be employed, the dimensions of the outmost orifice should be adapted leading to a thinner adhering layer, the ratio between the polymer solution and the amount of the first coagulation bath could be adapted by using different flow conditions, or by an enhanced convective transport in the second coagulation bath. In principle, increasing the temperature of the second bath could also enhance the removal of the first coagulant from the fiber, but since the change in temperature would change the thermodynamic and kinetic behaviour of the membrane formation process as well this has not been taken into consideration.

From the measured $P / l$ values and the permeability obtained for a PES film it can be calculated that the effective skin thickness of the fibers represented in Table 2 is $\sim 0.9 \mu \mathrm{m}$. By using other nonsolvents as the first coagulant and applying a different drying technique, PES fibers with a defect-free skin of $0.3 \mu \mathrm{m}$ could be realised [20].

The effect of variation in the flow ratio between the polymer solution and the first coagulation was examined. Table 3 shows that an increase in the flow rate of the first coagulant enhances the selectivity but the permeation rate is dropped. This is in accordance with the ex-

\section{TABLE 4}

Selectivity and $P / l$ values of PSf hollow fiber membranes spun with variable first nonsolvents for the separation of a $\mathrm{CO}_{2} /$ $\mathrm{CH}_{4}$ gas mixture

\begin{tabular}{llll}
\hline $\begin{array}{l}\text { First } \\
\text { nonsolvent }\end{array}$ & $\begin{array}{l}\text { Viscosity } \\
\text { nonsolvent } \\
(\mathrm{cP})\end{array}$ & $\begin{array}{l}\text { Contact time } \\
\text { nonsolvent } \\
(\mathrm{s})\end{array}$ & $\begin{array}{l}\text { Selectivity } \\
\alpha\left(\mathrm{CO}_{2} / \mathrm{CH}_{4}\right)\end{array}$ \\
\hline Glycerol & 945 & 0.8 & 26.0 \\
Glycerol/isopropanol, 80/20 (vol\%) & 281 & 1.1 & 24.4 \\
Glycerol/isopropanol, 50/50 & 45 & 1.1 & 24.1 \\
Glycerol/isopropanol, 20/80 & 8 & 1.1 & 19.5 \\
\hline
\end{tabular}

aviscosities are calculated according to ref. 24.

b $10^{-6} \mathrm{~cm}^{3} / \mathrm{cm}^{2} \mathrm{~s} \mathrm{cmHg}$.

Conditions. Spinning solution: $35 \%$ PES, $62 \%$ NMP, $3 \%$ glycerol; flow rate: $1.2 \mathrm{ml} / \mathrm{min}$; temperature: $48^{\circ} \mathrm{C}$. First coagulant: glycerol; flow rate: $3.5 \mathrm{ml} / \mathrm{min}$; temperature: $20^{\circ} \mathrm{C}$. Bore liquid: water; flow rate: $0.6 \mathrm{ml} / \mathrm{min}$; temperature: $20^{\circ} \mathrm{C}$. Second nonsolvent: water; temperature: $20^{\circ} \mathrm{C}$. 


\section{TABLE 5}

Selectivity and $P / l$ values of $\mathrm{PSf}$ hollow fiber membranes for the separation of a $\mathrm{CO}_{2} / \mathrm{CH}_{4}$ gas mixture as a function of the glycerol concentration in the polymer solution

\begin{tabular}{llllr}
\hline $\begin{array}{l}\text { Polymer } \\
\text { (PSf) } \\
\text { (wt\%) }\end{array}$ & $\begin{array}{l}\text { Additive } \\
\text { (glycerol) } \\
(\text { wt\%) }\end{array}$ & $\begin{array}{l}\text { Solvent } \\
\text { (NMP) } \\
(\mathrm{wt} \%)\end{array}$ & $\begin{array}{l}\text { Selectivity } \\
\boldsymbol{\alpha}\left(\mathrm{CO}_{2} / \mathrm{CH}_{4}\right)\end{array}$ & $\begin{array}{r}P / l^{\mathbf{a}} \\
\left(\mathrm{CO}_{2}\right)\end{array}$ \\
\hline 30 & 0 & 70 & 30.0 & 7.5 \\
30 & 5 & 65 & 33.1 & 10.3 \\
30 & 7 & 63 & 1.6 & 13.3 \\
\hline
\end{tabular}

${ }^{1} 10^{-6} \mathrm{~cm}^{3} / \mathrm{cm}^{2} \mathrm{~s} \mathrm{cmHg}$.

Conditions. Spinning solution: $30 \%$ PSf, $(70-x) \%$ NMP, $x \%$ glycerol; temperature: $48^{\circ} \mathrm{C}$. First coagulant: $80 / 20$ vol $\%$ glycerol/isopropanol; temperature: $22-24^{\circ} \mathrm{C}$. Bore liquid: water; temperature: $22-24^{\circ} \mathrm{C}$. Second nonsolvent: water; temperature: $22-24^{\circ} \mathrm{C}$. Contact time with the first coagulant: $0.8 \mathrm{~s}$.

\section{TABLE 6}

Selectivity and flux of PSf hollow fiber membranes spun with variable first nonsolvents for the dehydration of $80 \mathrm{wt} \%$ acetic acid by pervaporation at $70^{\circ} \mathrm{C}$

\begin{tabular}{lllll}
\hline $\begin{array}{l}\text { First } \\
\text { nonsolvent }\end{array}$ & $\begin{array}{l}\text { Viscosity } \\
\text { nonsolvent } \\
(\mathrm{cP})\end{array}$ & $\begin{array}{l}\text { Contact } \\
\text { time } \\
(\mathrm{s})\end{array}$ & Selectivity & $\begin{array}{l}\text { Flux } \\
\left(\mathrm{kg} / \mathrm{m}^{2} \mathrm{~h}\right)\end{array}$ \\
\hline $\begin{array}{l}\text { Glycerol } \\
\text { Glycerol/isopropanol, 80/20 }\end{array}$ & 945 & 0.8 & 42 & 0.130 \\
(vol.\%) & 281 & 1.1 & 44 & 0.132 \\
Glycerol/isopropanol, 50/50 & 45 & 1.1 & 40 & 0.135 \\
Glycerol/isopropanol, 20/80 & 8 & 1.1 & 33 & 0.170 \\
\hline
\end{tabular}

Conditions. Spinning solution: $35 \%$ PSf, $3 \%$ glycerol and $62 \%$ NMP; temperature: $67^{\circ} \mathrm{C}$. First coagulant: $(100-x) / x$ vol $\%$ glycerol/isopropanol; temperature: $22-24^{\circ} \mathrm{C}$. Bore liquid: water; temperature: $22-24^{\circ} \mathrm{C}$. Second nonsolvent: water; temperature: $22-24^{\circ} \mathrm{C}$. Spinning speed: $3.5-5 \mathrm{~m} / \mathrm{min}$

\section{TABLE 7}

Selectivity and flux of PSf hollow fiber membranes for the dehydration of $80 \mathrm{wt} \%$ acetic acid by pervaporation at $70^{\circ} \mathrm{C}$ as a function of the glycerol concentration in the spinning dope

\begin{tabular}{lllll}
\hline $\begin{array}{l}\text { Polymer } \\
\text { (PSf) } \\
\text { (wt\%) }\end{array}$ & $\begin{array}{l}\text { Additive } \\
\text { (glycerol) } \\
\text { (wt\%) }\end{array}$ & $\begin{array}{l}\text { Solvent } \\
\text { (NMP) } \\
(\mathrm{wt} \%)\end{array}$ & Selectivity & $\begin{array}{l}P / l^{\mathrm{a}} \\
\left(\mathrm{kg} / \mathrm{m}^{2} \mathrm{~h}\right)\end{array}$ \\
\hline 30 & 0 & 70 & 54 & 0.222 \\
30 & 5 & 65 & 65 & 0.285 \\
30 & 7 & 63 & 63 & 0.334 \\
\hline
\end{tabular}

Conditions. Spinning solution: $30 \%$ PSf, $(70-x) \%$ NMP, $x \%$ glycerol; temperature: $48^{\circ} \mathrm{C}$. First coagulant: $80 / 20$ vol\% glycerol/isopropanol; temperature: $22-24^{\circ} \mathrm{C}$. Bore liquid: water; temperature: $22-24^{\circ} \mathrm{C}$. Second nonsolvent: water; temperature: $22-24^{\circ} \mathrm{C}$. Contact time with the first coagulant: $0.8 \mathrm{~s}$. 
pectation that when the flow rate is high, the glycerol layer will be thick resulting in an effective longer contact time. Consequently this will lead to a high selectivity and low flux, as is shown in Table 3 . Together with the variation in flow rate shown in Table 3 the convective transport in the second coagulation bath was promoted by stirring. This enables us by comparing the results of Table 2 and those in Table 3 for the fiber with the similar spinning conditions to analyse the effect of enhanced convective transport. In conventional spinning this parameter is of less importance. It can be concluded that enhanced convective transport will lead to a larger permeation rate, but unfortunately that the selectivity has been dropped.

To study the influence of the viscosity of the first nonsolvent and to show that this modified dual-bath process can also be applied to other polymers, PSf hollow fiber membranes were prepared employing different mixtures of glycerol and isopropanol. These mixtures have a delay time of demixing larger than $1500 \mathrm{~s}$ [20]. Of course the delay time is a prerequisite in our method to prepare dense and defect-free top layers. The viscosities of the mixtures were calculated from the pure component viscosities according to the method proposed by Grunberg and Nissan [24]. The contact time with the first nonsolvent was kept constant. Selectivity and $P / l$ values of these PSf hollow fiber membranes are represented in Table 4.

From the results it can be concluded that with decreasing viscosity of the first nonsolvent and keeping the adjusted contact time with the nonsolvent constant, the $P / l$ value of the PSf hollow fiber increases. This has to be attributed to the fact that the first nonsolvent with the lower viscosity will be removed from the fiber wall faster compared to nonsolvents of higher viscosity, resulting in a smaller "adhering" time. A slight decrease in selectivity can also be observed, but this effect is not as significant as the increase in $P / l$.
From the obtained $P / l$ values and a permeability obtained for a dense PSf film, it can be calculated that the effective membrane thickness of the fibers given in Table 4 vary from 2.5 to $1.3 \mu \mathrm{m}$.

A further reduction of the effective membrane thickness may be achieved by a lower polymer concentration and a higher additive concentration in the spinning dope. In Table 5 selectivity and $P / l$ values of PSf hollow fiber membranes as a function of the additive concentration are represented. The polymer concentration was $30 \mathrm{wt} \%$.

Table 5 shows an increase in $P / l$ with an increasing additive (glycerol) concentration in the spinning dope. The calculated effective membrane thickness varies from 1.1 to $0.6 \mu \mathrm{m}$. The selectivities of the upper two membranes in Table 5 have reached the intrinsic value, while the latter one is almost non-selective. The composition of the polymer spinning dope in the latter case is so close to the bimodal composition that liquid-liquid demixing can already occur in the first nonsolvent bath giving the interfacial layer not enough time to form a dense defect-free top layer.

Comparison of the results obtained in Tables 4 and 5 indicates that the permeation rate drops when a too high polymer concentration is used. This can probably be attributed to an increase in resistance towards permeation in the support layer. These results also lead to the conclusion that by applying the dual-bath method all other spinning conditions still have to be optimized.

\subsection{Pervaporation}

Transport in the case of gas separation and pervaporation both take place according to the solution-diffusion mechanism. Therefore, hollow fiber membranes which are highly selective in gas separation should also be selective in pervaporation. The PSf hollow fibers used for 


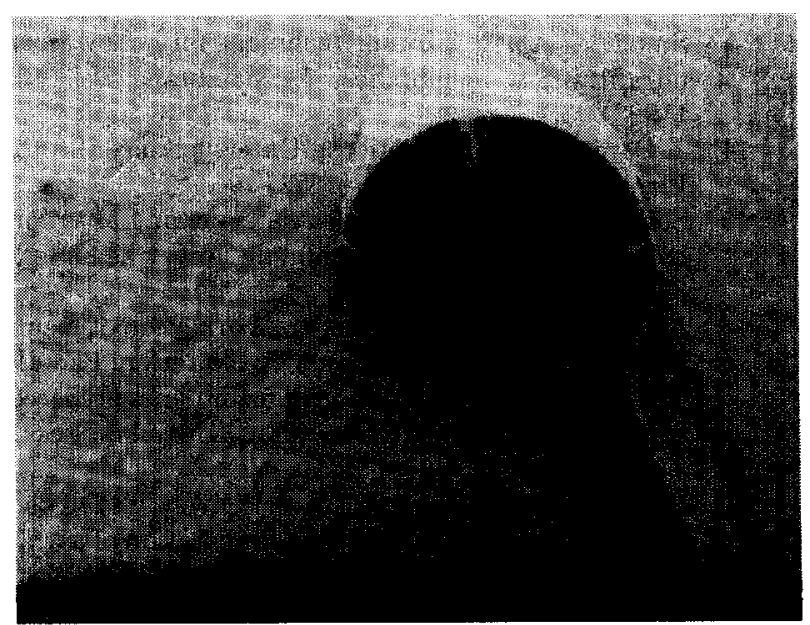

Cross section

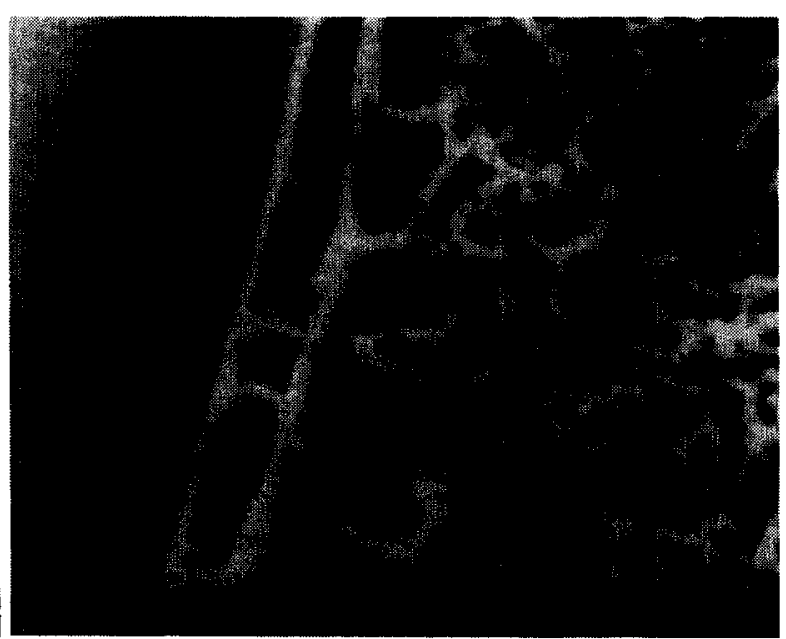

Outside toplayer

Fig. 3. Cross section and top layer of a PES hollow fiber membrane. Polymer solution: 35 wt\% PES, 55 wt\% NMP, 10 wt\% glycerol. Bore liquid: water. First nonsolvent: glycerol. Second nonsolvent: water.

gas separation were also applied in pervaporation. The separation properties for the dehydration of $80 \mathrm{wt} \%$ acetic acid of the PSf hollow fiber membranes where the first nonsolvent was varied are represented in Table 6.

Although the differences between the first three fibers are small compared to gas separation (Table 4), the same relation between first nonsolvent and flux can be observed in pervaporation: an increase in flux with decreasing viscosity. The selectivity of the upper three membranes is more or less the same, while the last one is less selective.

The increase in flux is more pronounced when the concentration of glycerol in the spinning dope is increased, as it can be concluded from the separation properties presented in Table 7 .

It is remarkable to see that the membrane which was almost non-selective in gas separation (Table 5) is still highly selective in pervaporation. This means that a low selectivity for gas separation is not automatically a low selectivity for pervaporation.

A SEM picture of the cross section and top layer of a typical PES hollow fiber membrane is given in Fig. 3.

A more extensive study of PSf hollow fiber membranes and the influence of spinning parameters on the ultimate pervaporation properties for the dehydration of acetic acid is published elsewhere [25].

\section{Conclusions}

It can be concluded that with the use of the triple orifice spinneret highly selective gas separation and pervaporation hollow fiber membranes of PES and PSf can be prepared. Integrally skinned hollow fiber membranes are obtained with effective skin thicknesses of 0.9 $\mu \mathrm{m}$ for PES and $0.8 \mu \mathrm{m}$ for PSf and intrinsic selectivity for the separation of a $\mathrm{CO}_{2} / \mathrm{CH}_{4}$ gas mixture. These thicknesses are considerably smaller than the ones obtained by applying the dual-bath method with a conventional tube-inorifice spinneret.

Although better performances can be obtained with this new spinning technique, the 
other spinning conditions should still be optimized to obtain good results.

\section{References}

1 I. Cabasso, Hollow-fiber membranes, in Kirk-Othmers Encyclopdia of Chemical Technology, Vol. 12, 1980, p. 492.

2 H.I. Mahon and B.J. Lipps, Hollow-fiber membranes, in Encyclopedia of Polymer Science and Technology, Vol. 15, Wiley, New York, 1971, p. 258

3 W.E. Skiens, B.J. Lipps, E.A. Mclain and D.E. Dubocq, Gas permeable membranes and process for making same, US Pat. 3,798,185 (1974).

4 C.R. Antonson, R.J. Gardner, C.F. King and D.Y. Ko, Analysis of gas separation by permeation in hollow fibers, Ind. Eng. Chem., Prod. Res. Dev., 16 (1977) 463.

5 A.J. Castro, Method for making microporous products, US Pat. 4,247,498 (1981).

6 J.M.S. Henis and M.K. Tripodi, Composite hollow fiber membranes for gas separation: the resistance model approach, J. Membrane Sci., 8 (1981) 233.

7 R.E. Kesting, Concerning the microstructure of dryRO membranes, J. Appl. Polym. Sci., 17 (1973) 1771.

8 K.V. Peinemann and I. Pinnau, Method for production of an integral asymmetric membrane with increased selectivity in gas separation, Ger. Pat. DE 3525235 (1986).

9 W.J. Koros and G.K. Fleming, Membrane-based gas separation, J. Membrane Sci., 83 (1993) 1.

10 I. Pinnau and W.J. Koros, Structures and gas separation properties of asymmetric polysulfone membranes made by dry, wet, and dry/wet phase inversion, J. Appl. Polym. Sci., 43 (1991) 1419.

11 I. Pinnau and W.J. Koros Influence of the quench medium on the structures and gas permeation properties of polysulfone membranes made by wet and dry/wet phase inversion, J. Membrane Sci., 71 (1992) 81.

12 I. Pinnau and W.J. Koros, Gas permeation properties of asymmetric poly (carbonate), poly (ester carbonate) and fluorinated poly (imide) membranes, J. Appl. Polym. Sci., 46 (1992) 1175.
13 I.M. Wienk, H.A. Teunis, T. v.d. Boomgaard and C.A. Smolders, A new spinning technique for hollow fiber ultrafiltration membranes, J. Membrane Sci., 78 (1993) 93.

14 J. Baranetzky, Diosmotische Untersuchungen, Ann. Phys. Chem. Leipzig, 147 (1872) 195.

15 S. Loeb and S. Sourirajan, Sea water demineralization by means of an osmotic membrane, Adv. Chem. Ser., 38 (1963) 117.

16 A.J. Reuvers and C.A. Smolders, Formation of membranes by means of immersion precipitation. Part II. The mechanism of formation of membranes prepared from the system CA/acetone/water, J. Membrane Sci., 34 (1987) 67.

17 R.M. Boom, J.A. van 't Hof, A.J. Reuvers, T. van den Boomgaard and C.A. Smolders, Preparation of asymmetric gas separation membranes with a high selectivity by a dual-bath wet spinning process, Proc. Int. Conf. Chem. Eng., Chemcon '89, Trivandrum, India, 12-17 December 1989.

18 J.A. van 't Hof, A.J. Reuvers, R.M. Boom, H.H.M. Rolevink and C.A. Smolders, Wet spinning of asymmetric gas separation membranes with high selectivity by a dual-bath coagulation method, J. Membrane Sci., 70 (1992) 17.

19 G.H. Koops, S.-G. Li, T. van den Boomgaard, M.H.V. Mulder and C.A. Smolders, Het spinnen van asymmetrische holle vezelmembranen met een dicht nietporeuze toplaag, resp. met zowel een poreuze toplaag als een poreuze onderlaag, Dutch Pat. 91.02151 (1991).

20 S.-G. Li, PhD Thesis, Preparation of Hollow Fiber Membranes for Gas Separation, University of Twente, Enschede, 1994.

21 P.K. Gantzel and U. Merten, Gas separation with highflux cellulose acetate membranes, Ind. Eng. Chem., Proc. Res. Dev., 9 (1970) 331.

22 D.L. Ellig, J.B. Althouse and F.P. McCandless, Concentration of methane from mixtures with carbon dioxide by permeation through polymeric films, J. Membrane Sci., 6 (1980) 259.

23 G.H. Koops, PhD Thesis, Dehydration of Acetic Acid by Pervaporation, University of Twente, Enschede, 1992.

24 L. Grunberg and A.H. Nissan, Mixture law for viscosity, Nature, 164 (1949) 799.

25 G.H. Koops, M.H.V. Mulder and C.A. Smolders, Integrally skinned polysulfone hollow fiber membranes for pervaporation, J. Appl. Polym. Sci., accepted. 